\title{
Capital social y humano en convergencia. Asentamientos irregulares de Milpa Alta
}

\author{
Gardy Augusto Bolívar Espinoza \\ Universidad Autónoma de México-Azcapotzalco, México D.F., México. \\ Email: abe88@hotmail.com \\ Óscar Rogelio Caloca Osorio \\ Universidad Nacional Autónoma de México, México D.F., México. \\ Email: oscarcalo8@yahoo.com.mx
}

Resumen: El capital social, si bien corresponde a una categoría nacida de la economía política clásica y, en particular, empleada por Karl Marx, se presenta en su versión contemporánea a través de los modelos de combinación del capital físico y el capital humano en el contexto de la teoría de la economía del bienestar. En la primera parte de este artículo se expone la cuestión conceptual y en la segunda parte se expone el capital humano en un modelo de crecimiento de Convergencia. Se consideran los niveles de escolaridad promedio en los asentamientos irregulares de la Delegación Milpa Alta en el Distrito Federal entre 2000-2005 y se proyectan las tasas al 2020 que mantiene los resultados de Convergencia obtenidos en el modelo para el 2000-2005, demostrando la relación entre valor, trabajo, educación y crecimiento.

Palabras clave: Capital social y humano, Convergencia, Asentamientos irregulares.

\section{Converging social and human capital. Irregular settlements of Milpa Alta}

\begin{abstract}
Social capital, although born as a category of classical political economy and, in particular, used by Karl Marx, is presented in its contemporary version by combining models of physical capital and human capital in the context of the theory of welfare economics. In the first part of this article the conceptual aspect is presented and on the second part the human capital is presented in a Convergence growth model. The average levels of schooling in informal settlements in the Milpa Alta delegation in Mexico City between 2000-2005 are considered, and rates are projected up to 2020, which maintain convergence results obtained in the model for 2000-2005, demonstrating the relationship between value, work, education and growth.
\end{abstract}

Keywords: Social and human capital, Convergence, irregular settlements.

\section{Capital social e humano em convergência. Assentamentos em Milpa Alta}

Resumo: O capital social, que, embora nascido é a categoria da economia 
política clássica e, em particular, usado por Karl Marx, é apresentado em sua versão contemporânea, combinando modelos de capital físico e capital humano em o contexto da teoria da economia do bem estar. A primeira parte apresenta a questão conceitual ea segunda parte é o capital humano em uma modelo de crescimento de convergência. São considerados níveis da escolaridade média em assentamentos informais na delegação Milpa Alta na Cidade do México entre 2000-2005 e projetada para 2020 as taxas de manutenção de resultados de convergência, obtidos no modelo para 2000-2005. Demonstra-se a relação entre o valor, trabalho, educação e crescimento. iregulares.

Palavras-chave: capital social e humano, convergência, assentamentos

El futuro de la humanidad no está ordenado de antemano por el espacio,

la energía y la tierra cultivable. Estará determinado por la evolución inteligente de la humanidad (Schultz, 1985: 15).

\section{Introducción}

Varios son los conceptos, como el de “inteligencia”, que se utilizan como facultad que se aplica a la solución de problemas conocidos y a la obtención de las mejores respuestas ante dilemas aún no resueltos que harían posibles un futuro alentador para la humanidad. Pero, ¿de qué clase de inteligencia se habla? Probablemente de la inteligencia de las mujeres y hombres preparados y respaldados por una formación educativa sólida.En este sentido, la inversión en educación es altamente probable que garantice la sustentación y el desarrollo de los seres humanos.

Dicha inversión en educación no es otra que uno de los principales componentes de lo que se ha discutido en torno al término de "capital humano”. Donde, la probabilidad de alcanzar el desarrollo económico depende de la inversión en capital humano. El capital humano, como toda inversión, se encuentra sujeta a la regla del costo de oportunidad, es decir, se invierte en capital humano acosta de dejar de invertir en otro sector.

En la concepción contemporánea, el desarrollo implica disponer de la libertad necesaria para que los individuos alcancen los objetivos previstos y entre estos está la posibilidad de alcanzar un nivel educativo de acuerdo con sus intereses y expectativas de vida futuras. Bajo la expectativa que la inversión en capital humano garantice la difusión y adquisición de conocimientos, así como la libertad deseada, ello a través de la autonomía que brinda una renta lo suficientemente elevada que permita satisfacer las necesidades de bienes y servicios que una vida cómoda lo permite -a la par de la inversión en investigación y desarrollo, la inversión en infraestructura y la inversión en procesos del aprehender para hacerlo que permiten, como motores del crecimiento, el aceleramiento del desarrollo económico de una nación región o localidad. 
Así, el capital humano como parte integral de los procesos de capitalización, se vislumbra como un mecanismo de inversión en uno mismo con la mira de que dicha capitalización implique en un futuro extraer un rendimiento mayor de la inversión en comparación con otros mecanismos de rendimiento del capital. Puesto que, de no conseguirse tal mayor rendimiento, el proceso educativo dejaría de ser una inversión viable tanto para los sectores de escasos recursos como de los sectores que cuentan con elevados recursos económicos.

Sin embargo, la capitalización en seres humanos implica que aquellos que invierten en su educación aporten conocimientos que retribuyan a la nación, región o localidad de que se trate. Esto al potenciar el conocimiento social a través de la difusión en goteo de dichos nuevos conocimientos individuales. En este sentido, es de esperarse que la formación de capital humano tenga también consecuencias como la reducción paulatina en el atraso educativo.

Ello se logra a través de los procesos de Convergencia en el sentido de que las regiones cuyos individuos cuentan con niveles educativos bajos aumenten sus niveles educativos con mayor grado de rapidez que aquellos sectores que ya cuentan con elevados niveles educativos. Esto no indica que los sectores con elevados niveles educativos ya no acumulen y utilicen más información, sino que el crecimiento de estos sectores en materia de educación crezca a una tasa menor que el crecimiento de la tasa educativa de los sectores con niveles educativos bajos.

De obtenerse lo anterior estaríamos hablando de que existe un proceso de Convergencia de la tasa educativa de los habitantes de una nación, región o localidad, en caso contrario se habla de Divergencia. El proceso de Convergencia es necesario para posibilitar un mayor crecimiento económico ya que la brecha entre aquellos individuos con tasas educativas más bajas paulatinamente tendería a igualarse con aquello que poseen altos niveles educativos.

El presente trabajo pretende extender el análisis de capital humano y el estudio de la convergencia a los habitantes de las localidades de asentamientos humanos irregulares que se registran en la delegación Milpa Alta en el Distrito Federal de México. Con la intención de que este tipo de estudio pueda será ampliado a más asentamientos humanos irregulares de América Latina.

Para lograr esto se plantean las siguientes cuatro secciones: en la primera sección, se busca establecer una conexión, entre el llamado capital social y capital variable de Karl Marx, estipulado en El Capital, con la reciente argumentación acerca del capital humano propuesta por Theodore W. Schultz. Posteriormente, en la siguiente sección, se formula el modelo extendido de Solow con capital humano. En la tercera sección se realiza la exposición sobre qué es un modelo de Convergencia y se procede a estimar los dos tipos de Convergencia, la beta y sigma convergencia, ello a través 
de las tasas de escolaridad promedio de los habitantes de los asentamientos humanos irregulares de la delegación Milpa Alta en el Distrito Federal (DF). Finalmente se establece un pronóstico hasta el 2020, respetando los resultados encontrados sobre Convergencia, para observar cual será la dinámica esperada en los asentamientos irregulares.

\section{La discusión conceptual}

Existen diversas maneras de determinar qué es un asentamientos irregular, pero la manera tradicional consiste en que un asentamiento es irregular cuando los procesos de adquisición de los predios no son adjudicados de manera legal o reconocidos por alguna instancia de gobierno, es decir, su adquisición es vía un mecanismo extralegal como la invasión de predios cuyo propietario es otro particular o el gobierno o cuya venta de los predios no se da en un marco jurídico legal reconocido por una instancia de gobierno.

En el caso de Milpa Alta muchos de los predios que son considerados irregulares han sido vendidos por propietarios comunales cuya venta no ha sido reconocida por una instancia de gobierno, pero que además se encuentran localizados fuera de los cascos urbanos. Donde, la delimitación entre los cascos urbanos y los llamados asentamientos irregulares de Milpa Alta se debió no a una cuestión normativa únicamente sino a una traza delimitada políticamente en donde se considero que quien se asentara dentro de la traza pertenece a los cascos urbanos regulares y quien se encontrara fuera de esa traza corresponde con los asentamientos irregulares.

Así, los asentamientos irregulares de Milpa Alta lo son principalmente porque son localidades no dentro de los cascos urbanos y cuya venta de terrenos no se les reconozca aún como parte de un mecanismo de compra-venta avalado por alguna instancia de gobierno, con la salvedad de que los comuneros son los dueños reconocidos del predio.

\section{A. Crecimiento y capital físico y humano}

Procedemos a exponer la idea sobre incluir el capital humano en el modelo tradicional de Solow ${ }^{1}$.

En este caso se parte del hecho que la producción, Y, en una economía se logra a través de la incorporación de capital físico, K, con el trabajo capacitado, $\mathrm{H}$, de acuerdo con la función de producción Cobb-Douglas de rendimientos constantes.

$$
Y=K^{\alpha}(A H)^{1-\alpha}
$$

Donde, A representa la tecnología de aumento del trabajo que crece en forma exógena a la tasa g. 
Los individuos en esta economía acumulan capital humano al dedicar tiempo al aprendizaje de nuevas habilidades, en lugar de trabajar. Así, si u representa la parte del tiempo de una persona dedicado a aprehender habilidades y L representa la cantidad total de trabajo bruto empleado para la producción en la economía. Suponemos que las habilidades de aprendizaje de la mano de obra no calificada, para el tiempo u, generan el trabajo capacitado $\mathrm{H}$ de acuerdo con:

$$
H=e^{\psi u} L
$$

Donde, $\psi$ es una constante positiva. Obsérvese que si $\mathrm{u}=0$ entonces $\mathrm{H}=\mathrm{L}$, es decir, todo el trabajo es no calificado -siguiendo a Marx todo el trabajo sería simple. Al aumentar u, una unidad de trabajo no calificado aumenta las unidades efectivas de trabajo calificado $\mathrm{H}$, es decir el trabajo se vuelve complejo pues está determinado por una exponencial de unidades de trabajo simple. Para ver de cuánto es el aumento se toman los logaritmos y las derivadas de la ecuación:

$$
\begin{gathered}
\operatorname{Iog} H=\psi u+\operatorname{Iog} L \\
\frac{d \log H}{d u}=\psi
\end{gathered}
$$

Esta ecuación expresa que un aumento pequeño en u aumenta $\mathrm{H}$ por el porcentaje $\psi$. El hecho de que los efectos son proporcionales está impulsado por la presencia del exponente "e" en la ecuación. La intención de esta formulación es comparar la afirmación de que un año adicional de estudios incrementa el salario percibido en alrededor de un 10\% (Jones, 2000: 49).

Ahora bien, se considera que el capital físico se acumula invirtiendo una parte de la producción en lugar de consumirla, así teniendo en consideración que:

$$
={ }_{S_{K}} Y-d K
$$

Donde, $\mathrm{s}_{\mathrm{K}}$ es la tasa de inversión para el capital físico, y d es la tasa de depreciación constante.

Solucionamos este modelo mediante las siguientes formulaciones: Primero, denotamos con letras minúsculas las variables que dividimos entre el trabajo no calificado, L, y reescribimos la función de producción en términos de producción por trabajador como:

$$
y=k^{\alpha}(A h)^{1-\alpha}
$$

Obsérvese que $\mathrm{h}=\mathrm{e}^{\psi u}{ }^{2}{ }^{2}$ En la misma forma que suponemos que las personas ahorran e invierten una parte constante de sus ingresos, se supondrá que u es constante y exógena. 
A lo largo de una ruta de crecimiento equilibrado, (y) y (k)crecerán a la tasa constante g, la tasa del progreso tecnológico. La solución del sistema se encuentra considerando la existencia de "variables de estado" que son constantes a lo largo de una ruta de crecimiento equilibrado. Estas son de la forma y/Ah y k/Ah que es posible ya que h es un término constante. En este sentido, la ecuación se transforma en:

$$
\tilde{y}=k^{\alpha}
$$

Así, escribiendo la ecuación de acumulación de capital de acuerdo con la variable de estado como:

$$
\tilde{k}=\mathrm{s} \tilde{y}-(\mathrm{n}+\mathrm{g}+\mathrm{d}) \tilde{k}
$$

Donde, $\mathrm{n}$ es la tasa de crecimiento natural de la población. Este modelo es similar a la dinámica tradicional del modelo básico de Solow (Jones, 2000, capítulo 2). Ello implica que cualquier dinámica de resultados aplicables al modelo básico de Solow también es aplicable a este modelo.

Así, los valores de estado estacionario de K y de ỹ se encuentran estableciendo $\mathrm{K}=0$, lo que da como resultado:

$$
\frac{\tilde{k}}{\tilde{y}}=\frac{s_{k}}{n+g+d}
$$

Que al sustituir esta condición en la función de producción $\widetilde{y}=\mathrm{K}^{\alpha}$ da como resultado el valor del estado estacionario de la razón de producción tecnológica $\widetilde{y}$ :

$$
\begin{aligned}
& \tilde{y}=\left(\frac{s_{k}}{n+g+d}\right)^{\propto} \tilde{y}^{\propto} \\
& \tilde{y}^{1-\propto}=\left(\frac{s_{k}}{n+g+d}\right)^{\propto} \\
& \widetilde{y^{\circ}}=\left(\frac{s_{k}}{n+g+d}\right)^{\frac{\alpha}{1-\alpha}}
\end{aligned}
$$

Así, reescribiendo esta ecuación en términos de producción por trabajador tenemos que:

$$
y^{\circ}(t)=\left(\frac{s_{k}}{n+g+d}\right)^{\frac{\alpha}{1-\alpha}} h A(t)
$$


Donde, se ha incluido explícitamente t para señalar las variables que están creciendo con el tiempo. Asimismo, esta última ecuación señala la explicación general para el modelo de Solow con capital humano sobre por qué existen naciones, regiones o localidades ricas y pobres. Estas diferencias se deben a que las regiones ricas, son ricas, porque tienen altas tasas de inversión en capital físico, dedican una gran parte del tiempo a la acumulación de habilidades, tienen bajas tasas de crecimiento de la población y tienen altos niveles de tecnología. En términos de Marx se dice lo siguiente, unas naciones, regiones o localidades son más ricas que otras porque dedican tiempo a la ampliación de unidades de trabajo simple.

\section{La aplicación del modelo}

\section{A. Cálculo de $\sigma$-Convergencia y $\beta$ Convergencia}

Una vez formalizado el modelo de crecimiento con capital humano y ver su importancia en la solución final de crecimiento; como tiempo que dedican las personas para aumentar sus habilidades. Se tiene que esta acumulación de habilidades provee de los mecanismos necesarios para determinar porque, en nuestro caso, las personas de unos y otros asentamientos irregulares tienen mejores condiciones de vida en comparación con los otros, derivado de las diferentes tasas educativas promedio.

Para observar lo anterior se procede a establecer un modelo de Convergencia, en particular se plantean dos enfoques uno obedeciendo al planteamiento de $\sigma$-Convergencia y el otro al de $\beta$-Convergencia. Así, la idea general de Convergencia es que las regiones más atrasadas tenderán a crecer más rápido que las más adelantadas, de tal suerte que la brecha entre estas disminuirá con el paso del tiempo.

Este tipo de planteamiento nos indica que es posible visualizar la Convergencia a través de $\sigma$-Convergencia y $\beta$-Convergencia ${ }^{3}$, donde, la primera hace referencia a la consideración de la evolución de las desviaciones estándar de la información para los periodos de tiempo que se tengan, esperando tener Convergencia si y sólo si las desviaciones estándar van disminuyendo con el tiempo en caso contrario hablaríamos de Divergencia.

La segunda refiere a que es posible visualizarla a través de un modelo en donde se considera necesario efectuar la siguiente regresión (Vilalta, 2003):

$$
\ln y_{t}-\ln y_{t-1}=\beta_{0}+\beta_{1} \ln _{t-1}+\varepsilon_{t}
$$

Donde, en nuestro caso, (y) es la variable educativa y en el entendido de que si el coeficiente $\beta_{1}$ es negativose hablade Convergencia y si es positivo estaríamos argumentando acerca de la existencia de Divergencia.

Para estimar estos dos planteamientos primero se considera la evo- 
lución general de la tasa de escolaridad promedio de los habitantes en los asentamientos irregulares de la delegación Milpa Alta (véase cuadro 1). ${ }^{4}$ Esta tasa considerada entre 2000-2005 refleja transformaciones de dos tipos: en el primero se agrupan todos los asentamientos irregulares que su resultado es negativo; en estos la escolaridad aumento, pues se está restando de los valores del 2000 los respectivos para el 2005. Esto ocurrió para 73 asentamientos irregulares que representan el 65 por ciento de la población.

En el segundo se encuentran reunidos el total de asentamientos donde el nivel promedio de escolaridad disminuyo y cuyo valor es positivo, lo cual ocurrió para el 35 por ciento de los asentamientos irregulares estudiados. Estos resultados preliminares llevan a suponer que debido a que los primeros son más que los segundos pudiese ser que si exista Convergencia, sin embargo, esta es una señal falsa porque bien pudiese ser que los asentamientos irregulares que aumentó el nivel educativo fuese los de mayor nivel y los que disminuyeron fuesen los de menor grado de escolaridad lo cual reflejaría una situación de divergencia.

Debido a lo anterior es que se plantea encontrar los resultados para $\sigma$-Convergencia y $\beta$-Convergencia. En el caso de la desviación estándar se tiene que para el 2000 esta es de 1.290035517 y para el 2005 de 1.238609765, lo cual refleja una disminución de la desviación estándar entre el 2000-2005, lo que induce a establecer que el nivel educativo promedio de los habitantes en los asentamientos irregulares de Milpa Alta presenta $\sigma$-Convergencia.

Ahora, para la determinación de $\beta$-Convergencia se encontró que la ecuación queda como sigue:

$$
\text { Iny }_{t}-\text { Iny }_{t-1}=1.29914901-0.65257878 \operatorname{In}_{t-1}+u_{t}
$$

Con lo cual, dado que el valor de $\beta_{1}$ es negativo, se habla de que las personas de los asentamientos irregulares de la delegación Milpa Alta experimentan de acuerdo con su tasa de escolaridad promedio $\beta$-Convergencia.

Por lo tanto, en función de que en ambas pruebas el sistema mostró contar con Convergencia, el sistema es Convergente y con ello, las personas de los asentamientos irregulares con tasas de escolaridad bajas alcanzarán a los individuos del resto de los asentamientos irregulares con tasas de escolaridad promedio mayores. Es por ello, que se elaboró un pronóstico para el 2010 y 2020, manteniendo la Convergencia indicada, para visualizar el panorama en los asentamientos irregulares de Milpa Alta.

\section{B. ¿Qué hay que esperar para el 2020? Predicción y Convergencia}

En los asentamientos irregulares de Milpa Alta ocurren diversos fenómenos respecto de la tasa promedio de escolaridad, los cuales corresponden con los siguiente: en un primer caso lo que se tiene es que en algu- 
nos asentamientos el nivel de escolaridad aumenta, lo cual corresponde principalmente con el hecho de que las mujeres en la delegación en general han recurrido cada vez más a los recursos educativos como medio para contar con recursos monetarios propios. Esto ha ocurrido a la par que muchos de los hombres han disminuido su concurrencia a la escuela aun cuando están en edad de asistir, muchos de ellos han recurrido a la formación de negocios que en la mayor parte de los casos les retribuyen los suficientes recursos para satisfacer sus necesidades; al grado de que se les conoce como "los burros de oro" es decir, personas con baja escolaridad pero con altos ingresos.

El tercer y último fenómeno que se experimenta es que las tasas de escolaridad promedio dependen también de los nuevos inquilinos, puesto que si estos cuentan con tasas de escolaridad elevadas le sumaran puntos a la localidad o asentamiento irregular de que se trate, pero si cuentan con tasas de escolaridad bajas o aún más bajas que las imperantes en el asentamientos, ergo, esto se traduce en una reducción en la tasa de escolaridad promedio.

Así, dependiendo del fenómeno que se trate es la explicación del comportamiento de la variable educativa usada, de cualquier manera la tendencia en Milpa Alta es a la convergencia pero bien no podría ser a tasas muy elevadas. Es por ello, que se elabora un pronóstico de la situación tomando en consideración una función que explique los cambios al alza o baja en los diferentes asentamientos y que conserve la lógica de $\sigma$-Convergencia y $\beta$-Convergencia encontradas.

Esto se resuelve a través de una función cúbica de la siguiente forma:

$$
Y=2.3807971 X-0.283437276 X 2+0.013176122 X 3
$$

Con esta se predicen los valores para las columnas de la escolaridad promedio para el 2010 y 2020. En el Cuadro, también se establece la diferencia que existe entre los indicadores para el 2010 y el 2020 del cual resulta que la distribución de proporciones de localidades donde ha aumentado la escolaridad es también de 73 y por ende,se mantiene la misma proporción de 65 por ciento.

Así, se hace necesario verificar si el pronóstico permite continuar identificando el proceso de Convergencia. Los resultados para $\sigma$-Convergencia y $\beta$-Convergencia son los siguientes. En el caso de la desviación estándar se tiene que para el 2010 esta es de 0.640483663 y para el 2020 de 0.524833071, lo cual refleja una disminución de la desviación estándar entre estos años, lo cual induce a establecer que el nivel educativo promedio de los habitantes en los asentamientos irregulares de Milpa Alta entre 2010-2020 presenta $\sigma$-Convergencia.

Ahora, para la determinación de $\beta$-Convergencia se encontró que la 
ecuación estipulada es la siguiente:

$$
\text { Iny }_{t}-\operatorname{Iny}_{t-1}=1.48210591-0.7403196 \operatorname{In}_{t-1}+u_{t}
$$

Dado que el valor de $\beta_{1}$ es negativo, entonces las mujeres y hombres que habitan en los asentamientos irregulares de la delegación Milpa Alta experimentan de acuerdo con su tasa de escolaridad promedio $\beta$-Convergencia. Esto vuelve sólido el argumento sobre la predicción realizada, al mantener ambos tipos de Convergencia para el 2010 y el 2020.

Ahora lo único que resta es observar si existe $\beta$-Convergencia entre el 2010 y el 2005. Donde una vez realizadas las estimaciones la ecuación resultante es la siguiente:

$$
\operatorname{Iny}_{\mathrm{t}}-\operatorname{Iny}_{\mathrm{t}-1}=1.54565901-0.78463014 \operatorname{In}_{\mathrm{t}-1}+\mathrm{u}_{\mathrm{t}}
$$

Lo cual refleja que el $\beta_{1}$ es negativo y por lo tanto existe $\beta$-Convergencia. Esto implica, para toda la serie desde el 2000 al 2020 , que el proceso de evolución de las tasas promedio de escolaridad de los habitantes de los asentamientos irregulares de Milpa Alta Converjan, y que con ello las disparidades disminuyan. Esto es en términos de Marx; la tendencia en los asentamientos irregulares de Milpa Alta es que exista paulatinamente menos la fuerza de trabajo simple y mayor el número de mujeres y hombres con unidades simples exponenciales o fuerza de trabajo compleja.

\section{Capital social y capital humano: volver a la sociología Marx: el campo desechado}

La perspectiva teórica del Capital, del siglo XIX, aparece alejada del capital social del siglo XXI. Ambas, con la misma raíz, sin embargo, pareciera que no se tocan, ni teórica ni prácticamente. Quizás, sería pertinente escudriñar esta relación.

Desde la década de los noventa, el tema del “capital social” ha sido visto por muchos estudiosos de la realidad social contemporánea como una propuesta promisoria, transversal y hegemónica. Tanto, desde la economía, las ciencias morales, la ciencia y la sociología política, como expertos de diversas instituciones internacionales han concurrido a este campo en busca de soluciones para el diseño de políticas públicas que es donde parece brillar más este concepto.

El “capital social”, sin embargo, —al contrario de su homónimo el capital de Marx - no tiene una sola vertiente epistemológica ni posee una sola biblia que lo anide y, más bien, se expresa en múltiples vulgatas que se esfuerzan por encontrar su significado. Dentro de estas diversas interpretaciones, sin embargo, el neoliberalismo económico, la perspectiva del rational choice y el individualismo metodológico parecieran tener un papel especial. Aunque, no es menos cierto, que el tema del capital social, 
también ha sido abordado por liberales y movimientos sociales progresistas que ven en él, modos de acceder a una mayor equidad y a más justas y solidarias relaciones sociales.

Teñido de aportes teóricos y metodológicos novedosos, el capital social, no está exento de referencias a clásicos antiguos y cercanos. Este hecho le da mayor amplitud y riqueza pero también contribuye a su oscuridad: definiciones vagas o, simplemente, falta de definición, situación que afecta seriamente los intentos de cuantificación. El "Capital social” se usa pero no se está muy claro que se entiende por él. Probablemente por que, en su comprensión, concurre oblicuamente la sociología clásica en temas tradicionales de la economía; y, está, vuelve a reconsidera su relación con la ciencia política. De ahí que no es extraño que se cite a menudo a Aristóteles, Rousseau, Smith, Tocqueville, y Durkheim, pero, poco se cita a Marx.

\section{El capital de Marx}

El capital de Marx es un concepto propio del siglo XIX y no tiene nada que ver con los conceptos contemporáneos de Capital en general ni menos del social. Marx no se podría haber preocupado de otras formas de capital como el capital tecnológico y no valoro ni al capital humano ni al social, otros fenómenos propios del capitalismo avanzado. Si algo tuviera que ver Marx en esta nueva teoría habría dos posibilidades: o se considera la obra de Marx como el lugar más apropiado para buscar los antecedentes primitivos, pero ya superado, de un "capital social” contemporáneo, o, con nostálgica persistencia se quisiera ver en Marx el verdadero fundador del concepto de "capital social” desde donde habría que iniciar cualquiera discusión teórica sobre el capital social actual.

\section{Capital social en Marx}

Por su parte, El Capital, producto de la Crítica a la Economía Política, ha sido fuente simbólica y heurística que se impuso como referente sagrado o demoníaco y que se sostuvo en el centro de la disputa ideológica, práctica y científica por lo menos hasta el último cuarto del siglo XX. Sus repercusiones políticas son evidentes y, en economía la relación valor-trabajo pareciera que tiene mucho que decir todavía. Sin embargo, en el plano de la sociología y de las políticas públicas, no aparecen claras sus posibles influencias. Habría que ver si esa ausencia es solamente aparente o si el tiempo ha relegado sus postulados a la crítica de los ratones.

El capitalismo de Marx, es una forma histórica, y su concepción podría inscribirse como la de uno de los más relevantes fundadores de las ciencias sociales, pero se vería mal como fundador de la sociología. Por su parte el "capital social”, sería una forma de comprender aquello de lo social que no es ni estructura jurídica ni política ni económica, y ver las relaciones sociales en sí mismas, como si fueran cosas, es decir, como sociolo- 
gía francesa clásica. Sin embargo, en Marx, el capital mercantil, el financiero, y el industrial son formas etéreas (abstractas), manifestaciones, metamorfosis de un mismo proceso del trabajo: el modo de producción capitalista. El capitalismo sería una forma como las relaciones económico- sociales, de “pertenencia obligatoria”, se desenvuelven, en una realidad presente determinada única diferente a otros modos de producción históricos.

La versión del siglo XIX sobre la noción de lo que es el capital social nos la ofrece vivamente Karl Marx,

El hecho de que el capital social sea la suma de los capitales individuales (incluidos los capitales por acciones y el capital del Estado, en la medida que los gobiernos emplean el trabajo asalariado productivo en las minas, ferrocarriles, etc., y funcionan como capitalistas individuales), y de que el movimiento total del capital social es igual a la suma algebraica de los capitales individuales (...) (Marx, 1977: 95-96 Tomo II)

El trabajo asalariado productivo es capital y en este caso es parte del capital social, el cual el mismo Marx identifica como el capital variable, donde, este no es otra cosa que el desembolso en salarios para los trabajadores asalariados. Empero, él también considerar la existencia del trabajo complejo o calificado, tal que

El trabajo complejo (skilledlabour, trabajo calificado) no es más que una potencia del trabajo simple, o más bien es apenas el trabajo simple multiplicado, de modo que determinada cantidad de trabajo complejo corresponde a una cantidad mayor del simple. (Marx, 1977: 63 Tomo I)

Esto es el trabajo calificado puede ser reducible, según Marx, al trabajo simple, puesto que este es la medida del valor. En este sentido, considera como factible la consideración de los trabajos complejos o calificados pero siempre y cuando puedan ser reducibles a unidades de trabajo simple, porque el trabajo complejo es una potencia del trabajo simple, es decir el trabajo simple elevado a un número determinado. Este es un acercamiento a la idea de formación y capacitación, de cómo la preparación de un individuo puede convertirse en la práctica de un trabajo calificado, que es comparable con un trabajo simple en su dimensión de suma de unidades de trabajo simple.

Sin embargo, no hay una noción explícita -aunque si implícita, al considerar que existen diferentes trabajos que reportan diferente número de unidades de trabajo simple debidas a las diferencias en la formación educativa, aunque algunos neo-marxistas si lo señalan-, de que el proceso educativo pueda ser estipulado como una forma específica de capitalizar a la fuerza de trabajo y determinado a través de una tasa de retorno. Ello, se debe principalmente al contexto en el cual se forman las ideas de Marx y las ideas de Schultz, puesto que las ideas de este último 
se guiaron por los procesos de recuperación desmedida en la época de la postguerra.

Con ello en mente, se tiene que la diferencia de contexto guarda para estos autores una diferencia en los argumentos que enarbolan -sin embargo, en el análisis, más abajo, sobre el capital humano incorporado al modelo de crecimiento de Solow es identificable que el capital humano dependen de una potencia de las unidades de trabajo bruto.

Ahora el concepto de capital humano es relativamente contemporáneo, data de 1960 cuando fue empleado por Theodore W. Schultz, sin embargo, su admisión propiamente dicha fue dos años después cuando el Journal of PoliticalEconomy público un suplemento sobre "Inversión en seres humanos” (Blaug, 1985: 250).

Dicho programa de investigación se basa fundamentalmente en una condición: se considera que las personas gastan en sí mismas de formas diversas buscando no solo el goce presente sino también los rendimientos futuros, donde estos

pueden ser considerados más como gastos en inversión que gastos de consumo, tanto si quien lo realiza es un individuo en beneficio propio o si los asume la sociedad a favor de sus miembros. El factor común es quien toma las decisiones está considerando el futuro como justificación de sus acciones presentes” (Blaug, 1985: 251-252).

Es decir, el núcleo básico de la idea de la formación en capital humano radica en que se pueda tener un futuro que reditúe más que el presente sin dicha formación. Esto abre la posibilidad de que el futuro pueda ser predecible y por ende que la incertidumbre sea menguada. Puesto que la incertidumbre es el principal obstáculo a vencer, con la formación en capital humano y en particular con su componente educativo es posible generar altas probabilidades de que el futuro pudiese ser mejor para aquellas personas que invierten en educación ${ }^{5}$.

Por supuesto que esto implica un proceso en el cual no es posible invertir en capital humano con bajos rendimientos, la idea es que esta inversión se haga en aquellos grupos de estudios que realmente permitan un incremento del nivel educativo que sea traducible en ingresos para los individuos en particular y lleno de beneficios sociales a través de la difusión del conocimiento. Así, "Para que el sistema funcione de manera eficiente ha de incrementarse la oferta de educación en campos de estudio que en la actualidad ofrecen una elevada tasa de rendimiento.” (Leyva y Cárdenas, 2002: 81).

Esto nos permite determinar, que la inversión en capital humano está condicionada, principalmente para aquellas profesiones que tienen un alto rendimiento. Sin embargo, la sociedad requiere del conocimien- 
to de diferentes profesiones que bajo este esquema están fuera de toda consideración, lo cual nos indica que el proceso de capitalización es selectivo.

Sin embargo, se considera que no sólo la eficiencia es un factor a tomar en cuenta, también hay que considerar el proceso de equidad, es por ello que los economistas defienden en cierto grado la existencia de financiamiento público de la educación (Leyva y Cárdenas, 2002: 81). Lo cual, implica que el proceso de capitalización contemple la posibilidad de que se generen las profesiones necesarias para mantener altos niveles culturales en una sociedad.

La equidad trae consigo la propagación del conocimiento. Por ende, fijando metas en la eficiencia y en la equidad es posible que por un lado, aquellos que desean recibir altos ingresos por su actividad laboral -una vez preparados-, y aquellos quienes desean contribuir al conocimiento social puedan en libertad alcanzar sus objetivos. ${ }^{6}$

Esto lleva a considerar que como motor del crecimiento el capital humano provee de los medios para garantizar una ruta para cerrar la brecha de desarrollo entre naciones, regiones o localidades y que puede ser expuesto como a continuación sigue.

\section{Conclusiones}

Las conclusiones son diversas, puesto que la temática lo permite, en primer lugar tenemos que, considerando las unidades de trabajo simple agregadas en trabajo complejo, es posible dar razón de las transformaciones de un análisis desde Marx a las consideraciones estipuladas por Schultz en la formación de capital humano.

Es importante destacar que el análisis del capital humano presentado no altera las condiciones que se reflejan en el modelo original de Solow, puesto que al agregar el capital humano la conclusión que se tiene es que las naciones, regiones o localidades son más ricas unas que las otras debido a que dedican una mayor parte de su tiempo al aprendizaje de habilidades para el trabajo, entre otras cosas.

El análisis de Convergencia provee de los mecanismos para saber si un sistema, en particular el de los habitantes de los asentamientos irregulares de Milpa Alta, están mejorando en sus condiciones educativas o no. En concreto se encontró que las mujeres y los hombres de este lugar si están mejorando sus condiciones pues pasan la prueba de tanto _-Convergencia como de _-Convergencia, es decir, sus tasas de escolaridad promedio Convergen y con ello, los más rezagados experimentaran un mayor crecimiento de sus tasas de escolaridad que los que están en mejor situación. 
Lo anterior pese a que existe estímulos económicos suficientes en la zona para que un buen porcentaje de hombres dejen de estudiar, pues esto bien puede verse compensado por las crecientes tasas de incorporación de las mujeres a ciclos educativos más elevados.

Resta decir, que si bien el proceso de generación de capital humano es atractivo para el desarrollo de una nación, región o localidad también es necesario atender que sin los empleos necesario que contraten a dicha fuerza de trabajo capacitada el proceso no se cerrara y se tendrán personas con alto grado de preparación con sueldos y salarios paupérrimos o que se encuentren desempleados o desempeñándose en alguna actividad diferente a lo estudiado, si este es el caso el modelo de capital humano falla en su cierre con la economía del trabajo.

\section{Características de los asentamientos irregulares de la delegación Milpa Alta: demografía y condiciones de las viviendas (2000 y 2005)}

Al parecer la delegación Milpa Alta, atrae una gran parte de la población de escasos recursos. La población total de los asentamientos irregulares creció cerca del doble proveniente de los asentamientos irregulares de los cascos urbanos, de su crecimiento natural y, en parte poco significativa, de nuevos inquilinos (véanse cuadros 1 y 2). La población femenina es mayor que la masculina y su crecimiento fue mayor en un punto.

El acceso a la salud creció tanto para la población derechohabiente como la que no lo es, aunque un poco menos esta última. Pero la población derechohabiente sólo corresponde a un cuarto de la no derechohabiente: en el 2000 la población sin derechohabiencia correspondía aproximadamente con un 76 por ciento y para el 2005 se permaneció casi constante con un 75\%. Ello refleja en gran medida que las condiciones de vida de una población que cuenta con escasos recursos y sin derechos a servicios de salud pública tiene que sortear innumerables dificultades para mantenerse en buenas condiciones físicas.

La población residente en otra entidad hace cinco años disminuyó, de hecho es poco significativa la proporción de población que vivía en otra entidad y se asentó en Milpa Alta, esto refuerza la idea de que la mayor parte de la población que se ubica en los asentamientos irregulares o corresponde con crecimiento natural de la delegación o vivía en otra delegación, esperando únicamente tener los recursos -pocos- necesarios para comparar un terreno barato o alquilar una vivienda barata en la delegación. Con esto se refuerza la idea de que lo atractivo de los asentamientos irregulares es que la población que adquiere un terreno allí busca contar con una vivienda en propiedad. 


\section{Cuadro 1 \\ Características demográficas en los asentamientos irregulares Absolutos y crecimiento Milpa Alta, 2000-2005}

\begin{tabular}{||l|l|l|l||}
\hline & $\begin{array}{l}2000 \\
\text { Absolutos }\end{array}$ & $\begin{array}{l}2005 \\
\text { Absolutos }\end{array}$ & $\begin{array}{l}\text { 2000-2005 } \\
\text { Crecimien } \\
\text { to }\end{array}$ \\
\hline Población total & 9374 & 16636 & 77.47 \\
\hline Población masculina & 4682 & 8278 & 76.80 \\
\hline Población femenina & 4692 & 8357 & 78.11 \\
\hline Población derechohabiente & 2039 & 3658 & 79.40 \\
\hline Población sin derechohabiente & 7136 & 12473 & 74.79 \\
\hline Población residente 1995-2000 & 7835 & 14237 & 81.71 \\
\hline Población residente en otra entidad 1995-2000 & 374 & 172 & -54.71 \\
\hline
\end{tabular}

Fuente: Elaboración propia con base en (INEGI, 2000 y 2005).

Las condiciones educativas en estos asentamientos corresponden con un incremento de casi tres puntos porcentuales de la población analfabeta, pero con una disminución en la inasistencia escolar por parte de l@s niñ@s que requieren asistir, este es un indicador alentador, puesto que permite observar que gran parte del crecimiento del analfabetismo se debe muy probablemente a el asentamiento de personas adultas sin estudios. Es por ello, que impactar sobre la educación tendría resultados satisfactorios para el crecimiento económico en la zona (véanse cuadros 3 y 4).

La anterior combinación se refleja en el hecho de que el grado promedio de escolaridad aumentó en el periodo de referencia, si bien, se encuentra por debajo del correspondiente a la delegación su incremento en 7.71 por ciento es un indicio favorable. Este indicio se debe básicamente a que más mujeres de la delegación se han incorporado a estudios medios y superiores.

\section{Cuadro 2}

\section{Características educativas en los asentamientos irregulares Absolutos y crecimiento Milpa Alta, 2000-2005}

\begin{tabular}{||l|l|l|l||}
\hline \hline & $\begin{array}{l}2000 \\
\text { Absolutos }\end{array}$ & $\begin{array}{l}2005 \\
\text { Absolutos }\end{array}$ & $\begin{array}{l}\text { 2000-2005 } \\
\text { Crecimiento }\end{array}$ \\
\hline Población analfabeta de 6 y más años & 776 & 796 & 2.58 \\
\hline Población que no asiste a la escuela de 5 a 12 años & 229 & 193 & -15.72 \\
\hline Grado promedio de escolaridad & 6.83 & 7.36 & 7.71 \\
\hline
\end{tabular}

Fuente: Elaboración propia con base en (INEGI, 2000 y 2005). 
Por otra parte, en cuanto al total de viviendas habitadas se tiene un vertiginoso incremento del 84.5 por ciento (véanse cuadros 5 y 6 ), es decir, en los asentamientos irregulares en sólo cinco años casi se duplica la cantidad de viviendas, esto nos indica que el flujo de personas que se asientan, tanto de la delegación Milpa Alta como de otras delegaciones, con la finalidad de contar en un futuro con una vivienda en propiedad es sumamente atractivo. Ahora, es deducible que existe desdoblamiento natural y que familiares que ya residían en los asentamientos irregulares de Milpa Alta también adquirieron un terreno y edificaron su vivienda puesto que el promedio de ocupantes por vivienda se redujo.

Sin embargo, la edificación de las nuevas viviendas no fue con materiales no precarios, puesto que creció en 30 por cien las viviendas que cuentan con piso de tierra. Sin embargo, la proporción de viviendas en estas condiciones paso de 18 por cien en el 2000 al 13 por ciento en el 2005, es decir en términos relativos disminuye la cantidad en proporción de viviendas con suelo de tierra, pero en términos absolutos, que es un indicador que muestra que tanto el problema a disminuido o aumentado, lo que se encuentra es ese aumento en viviendas en condiciones precarias de construcción.

Lo que es totalmente desfavorable es que las viviendas edificadas en realidad corresponden con una dinámica de “tugurización”, puesto que son viviendas sumamente pequeñas y que cuentan en su mayoría con un cuarto redondo o dos a lo sumo. Ello se observa en el hecho de que de las 1783 nuevas viviendas 256 sean de un cuarto y 444 de dos cuartos, es decir, que casi el 40 por ciento son viviendas precarias. Esto también indica que el 60 por ciento de las nuevas viviendas es altamente probable que no correspondan con familias en situación de precariedad extrema, ello, sin duda es parte de la heterogeneidad de los asentamientos irregulares de Milpa Alta.

\section{Cuadro 5}

Características de la vivienda en los asentamientos irregulares Absolutos y crecimiento Milpa Alta, 2000-2005

\begin{tabular}{|l|l|l|l||}
\hline & 2000 & 2005 & $2000-2005$ \\
\hline Total de viviendas habitadas & 2110 & 3893 & 84.50 \\
\hline Promedio de ocupantes por vivienda & 2.40 & 1.63 & -32.25 \\
\hline Viviendas con piso de tierra & 393 & 510 & 29.77 \\
\hline Viviendas de un cuarto & 384 & 640 & 66.67 \\
\hline Viviendas de dos cuartos & 531 & 975 & 83.62 \\
\hline
\end{tabular}

Fuente: Elaboración propia con base en (INEGI, 2000 y 2005).

Pero observemos las condiciones en la dotación de los servicios, lo cual, con seguridad nos indicará que aunque algunas nuevas viviendas no se construyan en condiciones precarias pueden no contar con algunos de 
los servicios necesarios para una vida satisfactoria. Simplemente por el hecho de que la dotación de los mismos no está extendida a este tipo de asentamientos (véanse cuadros 7 y 8).

Las viviendas sin servicio sanitario creció sólo en tres unidades lo cual indica que casi todas las nuevas viviendas si cuentan con este servicio, sin embargo, en materia de agua al interior de la vivienda vemos que las viviendas sin este servicio aumento en 73 por ciento, lo cual, es indicativo de que los asentamientos irregulares de Milpa Alta padecen por un desarrollo urbano raquítico, ya que la dotación de agua no están al alcance de las viviendas de dichos sitios. Ello, también refleja que buena parte de viviendas no construidas con materiales precarios no cuentan con la dotación del servicio, lo cual las sitúa dentro de las viviendas deficitarias y por ende con condiciones menores de vida.

Asimismo, las viviendas sin drenaje disminuyeron considerablemente, de hecho se puede considerar que sólo una pequeña parte de las viviendas nuevas no cuentan con drenaje, que seguramente son las más distantes de los cascos urbanos. Pero de qué sirve tener servicio sanitario y drenaje si no se cuenta con el elemento principal: agua potable al interior de las viviendas, claro es que la solución remite al uso de “pipas” transportadoras de agua, lo cual muestra el grado de atraso de estos asentamientos en materia urbana.

Empero, la dotación de electricidad disminuyó al incrementarse el número de viviendas que no cuentan con el servicio, esto es, una parte muy significativa de las nuevas viviendas no cuentan con electricidad, están construidas con materiales precarios, y no tienen agua, esto es un claro indicio de atraso. Sin embargo, esto no ocurre de manera similar para todos los pobladores de los asentamientos irregulares de la delegación, puesto que aquellas personas que se encuentran viviendo cerca de los cascos urbanos y pertenecen a los llamados "originarios"7 , pueden tener los servicios a diferencia a aquellos que no son “originarios” de la zona.

Por otra parte, en cuanto a la tenencia de bienes y en particular de tres bienes: televisión, refrigerador y lavadora (véanse cuadros 7 y 8), se puede observar que las viviendas en asentamientos irregulares sin televisión se incrementaron, muy probablemente están contempladas aquellas que no cuentan con el servicio de energía eléctrica de manera regular.

Pero las viviendas sin refrigerador aumentaron en casi 40 por ciento, lo cual, aunado a que un 42 por cien de las viviendas de estos asentamientos no cuentan con lavadora, reflejan que las condiciones económicas, de gran parte de la población de las nuevas viviendas de los asentamientos irregulares, no son del todo favorables, puesto que no cuentan con los votos monetarios para la adquisición de estos bienes necesarios, el espacio y la dotación de servicios: para que tengo una televisión y/o refrigerador sino tengo energía eléctrica, para que tengo una lavadora si con trabajos me dotan las “pipas” de agua. Es decir para la mayor parte de 
la población las condiciones son paupérrimas.

\section{Cuadro 7 \\ Características de los servicios e infraestructura de las viviendas en los asentamientos irregulares \\ Absolutos y porcentaje Milpa Alta, 2000-2005}

\begin{tabular}{||l|l|l|l||}
\hline \hline & 2000 & 2005 & $2000-2005$ \\
& ABSOLUTOS & ABSOLUTOS & CRECIMIENTO\% \\
\hline Sin servicio sanitario & 267 & 270 & 1.12 \\
\hline Sin agua interior & 949 & 1646 & 73.45 \\
\hline Sin drenaje & 1007 & 383 & -61.97 \\
\hline Sin electricidad & 97 & 197 & 103.09 \\
\hline Sin TV & 278 & 314 & 12.95 \\
\hline Sin refrigerador & 1388 & 1897 & 36.67 \\
\hline Sin lavadora & 1524 & 2177 & 42.85 \\
\hline
\end{tabular}

Fuente: Elaboración propia con base en (INEGI, 2000 y 2005).

Lo anterior puede también ser visualizado a partir de una estimación del desarrollo humano en los asentamientos irregulares ${ }^{8}$. De la estimación se tiene que entre el 2000 y el 2005 el nivel de desarrollo humano aumento y que con ello la precariedad disminuyó ${ }^{9}$. Sin embargo, este aumento es precario y apunta principalmente a las condiciones de educación más que de esperanza de vida, de hecho si tomamos en cuenta las características ya vistas de la vivienda, es probable que el índice en algunas zonas decayera.

Pero aún sin tomar en consideración esto último, el índice refleja que para algunos de los asentamientos este fue el caso: baja esperanza de vida debida a una raquítica atención médica como se vio en los niveles de derechohabiencia, bajos niveles educativos y de asistencia escolar, todo ello apunta a que la situación en algunas zonas empeoro por mucho que en otras haya mejorado.

Así, se tiene que para el 2000-2005 el nivel de desarrollo humano muy alto ${ }^{10}$ disminuyó de dos a un solo asentamiento lo cual corrobora lo dicho con anterioridad acerca de que en algunas zonas la situación empeoro. Ahora bien, los asentamientos que se encuentran con mayor grado de dificultad son los que van desde los niveles de medio hasta muy bajo desarrollo humano, los cuales para el 2000 correspondieron con el 79.46 por ciento, esto refleja el grado de deterioro de las condiciones de vida de la población en el respectivo año. Por lo dicho hasta ahora es de esperarse que este porcentaje haya disminuido para el 2005 y de hecho es así, puesto que este corresponde con el 57.14 por ciento (véase cuadro 9).

Esto nos indica que por mucho que exista una medida relativa, que solo toma en consideración a los asentamientos irregulares de la delega- 
ción Milpa Alta, los resultados de precariedad extrema alcanzan al cincuenta por ciento de la población. El número de asentamientos que registran esto situación entre el 2000 y 2005, para asentamientos humanos irregulares comparables, pasa de 89 a 69. Esto es reflejo del proceso de consolidación de los asentamientos más viejos y no de los nuevos que como ya se observó son cerca del cuarenta por ciento.

\section{Cuadro 9}

Niveles de desarrollo humano en los asentamientos irregulares. Milpa Alta 200-2005

\begin{tabular}{||l|l|l|l|l||}
\hline Nivel de desarrollo humano & 2000 & 2005 \\
\hline Relativo & Cantidad & Porcentaje & Cantidad & Porcentaje \\
\hline Muy bajo desarrollo humano & 16 & 14.29 & 4 & 3.57 \\
\hline Bajo desarrollo humano & 20 & 17.86 & 9 & 8.04 \\
\hline Medio bajo desarrollo humano & 31 & 27.68 & 15 & 13.39 \\
\hline Medio alto desarrollo humano & 22 & 19.64 & 36 & 32.14 \\
\hline Alto desarrollo humano & 21 & 18.75 & 47 & 41.96 \\
\hline Muy alto desarrollo humano & 2 & 1.79 & 1 & 0.89 \\
\hline TOTAL & 112 & 100.00 & 112 & 100.00 \\
\hline \hline
\end{tabular}

Fuente: Elaboración propia con base en (INEGI, 2000 y 2005).

Este proceso en el que a pesar de existir un incremento en el desarrollo humano general se manifiesta que en algunas zonas las condiciones de vida de la población se deterioro se debe principalmente a los nuevos residentes de los asentamientos humanos tanto de los que vivían ya en la delegación como en otras delegaciones del Distrito Federal.

Así, de acuerdo con las diferencias en las distancias porcentuales que experimentaron los pobladores son negativas todas aquellas en las que se mejoro su situación y que tienden a acercarse a un valor porcentual de cero (véase cuadro 10). Por el contrario, todos aquellos valores que en la diferencia entre 2005 y 2000 son positivos lo que nos indica es que se dio un deterioro en el desarrollo humano de los pobladores del asentamiento y a su vez aquellos cuyo parámetro aunque haya sido negativo pero tienden a acercarse al 100 sufren de un alto deterioro en su desarrollo humano, por ende, un valor positivos en la diferencia y un parámetro cercano a 100 permite argumentar que en este asentamiento sus pobladores se encuentran en una precariedad extrema creciente.

El total de asentamientos que experimentaron una situación de disminución de su desarrollo humano son 26. En particular las zonas que experimentan una precariedad extrema porque aparte de tener un alto porcentaje también disminuyó.

El desarrollo humano de sus habitantes son: La Mora V, Teatlaco, Tlaxiomulco, Prolongación Justo Sierra y AA Milpa Alta, es decir casi una 
quinta parte del total de asentamientos donde sus pobladores experimentaron reducción en su desarrollo humano. Así que si se pretendiese establecer una política de incremento del desarrollo humano; en principio tiene que ser apuntalando las variables educativas para elevar el nivel de vida de los pobladores de estos cinco asentamientos

\section{Cuadro 10 \\ Distancias porcentuales \\ de los asentamientos irregulares comparables Delegación Milpa Alta 2000-2005.}

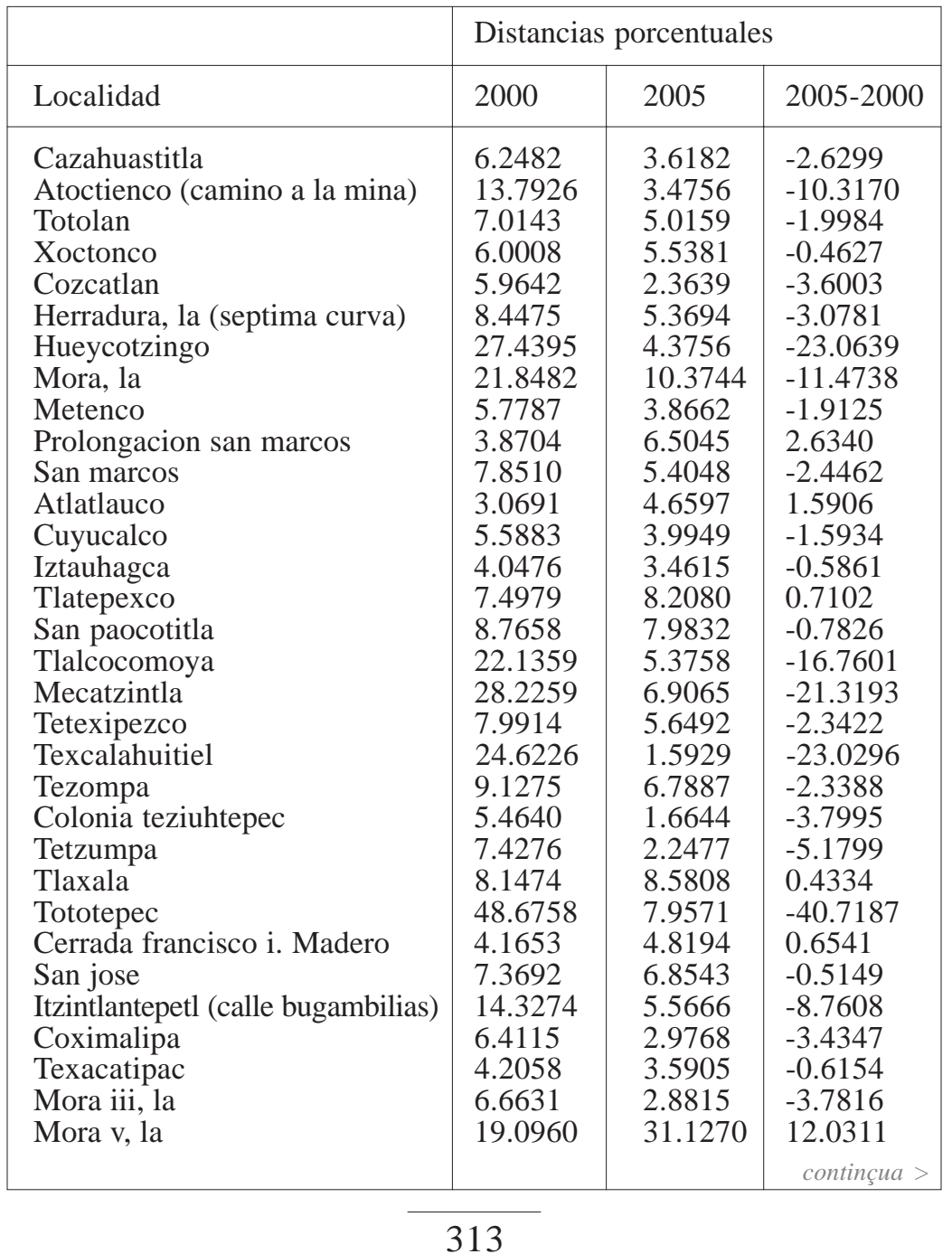




\begin{tabular}{|l|l|l|l|}
\hline Coyocalli & 6.6959 & 4.9572 & -1.7387 \\
Tlapalan & 2.8503 & 2.3462 & -0.5042 \\
Texalco & 9.4215 & 6.0585 & -3.3630 \\
Quepilco & 7.5882 & 4.9132 & -2.6750 \\
Barranca seca (pozo 8 camino & & & \\
a san francisco) & 7.6153 & 1434 & -4.4719 \\
Teatlaco & 17.4695 & 35.2835 & 17.8139 \\
Tlaloxtoc (ejidos de tecoxpa) & 7.1348 & 4.3876 & -2.7472 \\
Atuzanco & 3.2403 & 2.1597 & -1.0805 \\
Jalisco uno & 6.7004 & 3.3362 & -3.3642 \\
San lorenzotlacoyucan & 6.7705 & 3.8457 & -2.9248 \\
Rinconada del tioca & 3.9406 & 2.8030 & -1.1377 \\
Temoclaluca & 5.9220 & 2.2709 & -3.6511 \\
Coametzu & 20.6392 & 15.4175 & -5.2217 \\
Cuauhtunco & 4.0333 & 2.7788 & -1.2546 \\
Tepetenco & 4.6406 & 3.5156 & -1.1250 \\
San isidro cuatepec & 8.1677 & 4.0369 & -4.1308 \\
Xaluis (ixtahuaca) & 4.5795 & 3.6440 & -0.9354 \\
Tlacaxalt & 3.7393 & 3.8473 & 0.1081 \\
Tlachachalipac & 91.8366 & 34.8475 & -56.9891 \\
Camino real a tlaltenami & 3.6535 & 2.6496 & -1.0039 \\
Mecalco & 8.0957 & 4.1787 & -3.9170 \\
Carretera a santa ana & 4.0588 & 5.0995 & 1.0407 \\
Prolongacion insurgentes (xali) & 6.1246 & 6.1483 & 0.0237 \\
Zacaxontlicpa & 5.4439 & 3.1131 & -2.3308 \\
Santa catarina (piedra blanca) & 4.6825 & 6.0057 & 1.3232 \\
Paraje cuauhtetec & 15.5028 & 4.4791 & -11.0237 \\
Tetzmititla & 8.9179 & 5.0829 & -3.8350 \\
Tlaxiomulco & 12.4854 & 23.0833 & 10.5979 \\
Tepachac & 3.2829 & 2.1772 & -1.1057 \\
Tecoloxtitla & 13.1208 & 3.7539 & -9.3669 \\
Tapalaco & 4.9457 & 2.2140 & -2.7317 \\
Teacalco & 8.2566 & 2.7336 & -5.5231 \\
Conzontlicpa & 12.7179 & 4.5224 & -8.1955 \\
Huepaltepec & 4.7162 & 5.9462 & 1.2301 \\
Tecupilco (km. 17.5) & 3.6543 & 4.7736 & 1.1193 \\
Xaltepetitla & 1.6801 & 1.6614 & -0.0187 \\
Tetecolok & 64.8695 & 3.0109 & -61.8587 \\
Tlaxicoapa (mulotla) & 1.5640 & 4.0247 & 2.4607 \\
Santa rosa & 10.1787 & 2.3465 & -7.8322 \\
Prolongacionzaragoza & 11.1205 & 4.6767 & -6.4438 \\
Playa quieta & 11.8669 & 4.3509 & -7.5160 \\
Zapote,el & & & \\
(prol. Lazarocardenasxochitepec) & 4.4823 & 3.5844 & -0.8979 \\
Maxulco (barrio cruztitla) & 10.6617 & 3.3474 & -7.3143 \\
Prolongacionbelisariodominguez & & & \\
(el pirul) & 11.7652 & 12.5485 & 0.7833 \\
Prolongacion avenida mexico norte & 21.6433 & 8.4211 & -13.2222 \\
& & & \\
\hline
\end{tabular}




\begin{tabular}{|l|l|l|l|}
\hline Zacuaztitla & 8.0616 & 3.7121 & -4.3496 \\
Omaxal & 7.1757 & 6.2275 & -0.9482 \\
Ahuatitla (prolongacionbenitojuarez) & 2.3956 & 5.8748 & 3.4791 \\
Chichilecas & 5.1190 & 3.4713 & -1.6477 \\
Calle capulines & 10.2834 & 13.0062 & 2.7228 \\
Rancho los capulines & 27.2872 & 11.7432 & -15.5440 \\
Prolongacionxolotl & 8.0053 & 2.6763 & -5.3290 \\
Meliaxco & 6.6261 & 9.6161 & 2.9899 \\
Prolongacion las cruces & 16.2388 & 4.0450 & -12.1938 \\
Cuapalipa & 15.0792 & 13.1646 & -1.9146 \\
Camino tigustitla & 7.0096 & 9.5256 & 2.5160 \\
Zacaticli & 11.9468 & 8.0414 & -3.9055 \\
Tecpallo & 20.3243 & 5.3228 & -15.0014 \\
Nuhuaca (techinantitle) & 6.1346 & 2.6232 & -3.5114 \\
Cuacuahotlipa & 9.2961 & 3.3242 & -5.9719 \\
Prolongacionni_osheroes & 9.1677 & 3.1697 & -5.9980 \\
Paraje huicalco & 4.5526 & 3.4100 & -1.1425 \\
Tetexaloca & 9.7426 & 5.9952 & -3.7474 \\
Prolongacion justo sierra & 4.4400 & 15.4883 & 11.0483 \\
Acatlaco & 10.1975 & 8.1494 & -2.0481 \\
Paraje oluca & 9.0026 & 6.4857 & -2.5169 \\
Camino viejo a santa cruz & 4.9300 & 4.3934 & -0.5367 \\
Paraje la cruz (camino a tlaltenami) & 10.1932 & 5.4333 & -4.7598 \\
Zacamoli & 3.0184 & 3.3746 & 0.3562 \\
Sin nombre & 5.3788 & 5.0299 & -0.3490 \\
Tlaltepec & 4.6862 & 6.2404 & 1.5542 \\
Palmas, las & 6.1752 & 7.7625 & 1.5872 \\
Aa milpa alta & 1.5200 & 13.4413 & 11.9213 \\
Huexcomatepec & 3.8498 & 2.9481 & -0.9017 \\
Zozotlac & 2.6222 & 5.6413 & 3.0191 \\
Atoctenco (tlalaxco) & 4.1517 & 3.6421 & -0.5096 \\
Tlacopanco & 4.3942 & 4.5013 & 0.1071 \\
Pitucaltitla & 19.9706 & 15.2481 & -4.7225 \\
Localidades de una vivienda & 8.8437 & 2.7141 & -6.1296 \\
Localidades de dos viviendas & 11.8590 & 4.4577 & -7.4012 \\
\hline
\end{tabular}

Fuente: Elaboración propia con base en (INEGI, 2000 y 2005). 
Polis, Revista Latinoamericana, Volumen 11, No 33, 2012

\section{Escolaridad y Asentamientos irregulares}

\section{Preparatoria}

\begin{tabular}{|c|c|c|c|c|c|c|}
\hline \multirow[b]{2}{*}{ Metenco } & \multicolumn{2}{|c|}{$\begin{array}{l}\text { ESCOLARIDAD } \\
\text { PROMEDIO }\end{array}$} & \multirow{2}{*}{$\begin{array}{r}\text { DIFERENCIA } \\
2000-2005\end{array}$} & \multicolumn{2}{|c|}{$\begin{array}{l}\text { ESCOLARIDAD } \\
\text { PROMEDIO }\end{array}$} & \multirow{2}{*}{$\begin{array}{r}\text { DIFERENCIA } \\
2010-2020\end{array}$} \\
\hline & 2000 & 2005 & & 2010 & 2020 & \\
\hline Tlaltepec & 10 & 7.37 & 2.63 & 8.64 & 7.426 & 1.215 \\
\hline Santa Catarina & & & & & & \\
\hline (Piedra Blanca) & 9.29 & 10.24 & -0.95 & 8.22 & 8.807 & -0.587 \\
\hline Coximalipa & 9.14 & 7.69 & 1.45 & 8.143 & 7.539 & 0.604 \\
\hline Tlapalan & 9 & 8.68 & 0.32 & 8.074 & 7.927 & 0.147 \\
\hline Camino Real & & & & & & \\
\hline a Tlaltenami & 9 & 6.35 & 2.65 & 8.074 & 7.063 & 1.011 \\
\hline Cuauhtunco & 8.86 & 8.04 & 0.82 & 8.008 & 7.668 & 0.341 \\
\hline Tlacopanco & 8.81 & 8.3 & 0.51 & 7.985 & 7.769 & 0.217 \\
\hline Atlatlauco & 8.56 & 7.14 & 1.42 & 7.876 & 7.345 & 0.53 \\
\hline Cerrada Francisco & & & & & & \\
\hline I. Madero & 8.55 & 9.37 & -0.82 & 7.871 & 8.263 & -0.391 \\
\hline Atoctenco & & & & & & \\
\hline (Tlalaxco) & 8.55 & 9.18 & -0.63 & 7.871 & 8.163 & -0.292 \\
\hline Zozotlac & 8.17 & 5.92 & 2.25 & 7.717 & 6.895 & 0.823 \\
\hline Tlacaxatl & 8.05 & 7.81 & 0.24 & 7.671 & 7.582 & 0.089 \\
\hline
\end{tabular}


Secundaria

\begin{tabular}{|c|c|c|c|c|c|c|}
\hline \multirow[b]{2}{*}{ Xaluis (Ixtahuaca) } & \multicolumn{2}{|c|}{$\begin{array}{l}\text { ESCOLARIDAD } \\
\text { PROMEDIO }\end{array}$} & \multirow{2}{*}{$\begin{array}{l}\text { DIFERENCIA } \\
2000-2005\end{array}$} & \multicolumn{2}{|c|}{$\begin{array}{l}\text { ESCOLARIDAD } \\
\text { PROMEDIO }\end{array}$} & \multirow{2}{*}{$\begin{array}{l}\text { DIFERENCIA } \\
2010-2020\end{array}$} \\
\hline & 2000 & 2005 & & 2010 & 2020 & \\
\hline Rinconada del Tíoca & 7.92 & 8.39 & -0.47 & 7.623 & 7.805 & -0.182 \\
\hline Chichilecas & 7.88 & 7.74 & 0.14 & 7.608 & 7.557 & 0.051 \\
\hline Cozcatlán & 7.77 & 8.72 & -0.95 & 7.568 & 7.945 & -0.377 \\
\hline Jalisco Uno & 7.77 & 8.79 & -1.02 & 7.568 & 7.976 & -0.409 \\
\hline Huexcomatepec & 7.77 & 6.15 & 1.62 & 7.568 & 6.986 & 0.581 \\
\hline Iztauhagca & 7.7 & 8.35 & -0.65 & 7.542 & 7.789 & -0.246 \\
\hline Tlaxicoapa (Mulotla) & 7.7 & 7.59 & 0.11 & 7.542 & 7.503 & 0.039 \\
\hline Paraje Huicalco & 7.69 & 8.7 & -1.01 & 7.539 & 7.936 & -0.397 \\
\hline Calle Capulines & 7.67 & 5.25 & 2.42 & 7.532 & 6.594 & 0.938 \\
\hline Tecupilco (Km. 17.5) & 7.65 & 9.33 & -1.68 & 7.525 & 8.241 & -0.717 \\
\hline Camino Tigustitla & 7.62 & 6.78 & 0.84 & 7.514 & 7.219 & 0.295 \\
\hline Meliaxco & 7.61 & 7.24 & 0.37 & 7.51 & 7.38 & 0.13 \\
\hline $\begin{array}{l}\text { La Herradura } \\
\text { (Séptima Curva) }\end{array}$ & 7.57 & 7.23 & 0.34 & 7.496 & 7.377 & 0.119 \\
\hline Tapalaco & & & & & & \\
\hline (Amacapultitla) & 7.57 & 8.25 & -0.68 & 7.496 & 7.749 & -0.253 \\
\hline \multicolumn{7}{|l|}{ El Zapote (Prol. Lázaro } \\
\hline Cárdenas Xochitepec) & 7.5 & 8.13 & -0.63 & 7.471 & 7.702 & -0.231 \\
\hline \multicolumn{7}{|l|}{ Prolongación } \\
\hline Niños Héroes & 7.42 & 7.89 & -0.47 & 7.443 & 7.612 & -0.168 \\
\hline AA Milpa Alta & 7.38 & 6.3 & 1.08 & 7.429 & 7.044 & 0.385 \\
\hline Tetexipezco & 7.37 & 7.5 & -0.13 & 7.426 & 7.471 & -0.046 \\
\hline Sin Nombre & 7.37 & 6.48 & 0.89 & 7.426 & 7.111 & 0.315 \\
\hline \multicolumn{7}{|l|}{ Prolongación } \\
\hline Insurgentes (Xali) & 7.36 & 6.39 & 0.97 & 7.422 & 7.078 & 0.344 \\
\hline Tepachac & 7.36 & 8.22 & -0.86 & 7.422 & 7.737 & -0.315 \\
\hline Las Palmas (Chimeo) & 7.36 & 6.44 & 0.92 & 7.422 & 7.096 & 0.326 \\
\hline Cazahuastitla & 7.34 & 7.4 & -0.06 & 7.415 & 7.436 & -0.021 \\
\hline Tecoloxtitla & 7.29 & 8.77 & -1.48 & 7.398 & 7.967 & -0.57 \\
\hline Xaltepetitla & 7.29 & 7.42 & -0.13 & 7.398 & 7.443 & -0.045 \\
\hline San José & 7.28 & 6.99 & 0.29 & 7.394 & 7.293 & 0.101 \\
\hline \multicolumn{7}{|l|}{ Localidades de } \\
\hline una vivienda & 7.26 & 8.41 & -1.15 & 7.387 & 7.813 & -0.426 \\
\hline Tezompa & 7.23 & 6.9 & 0.33 & 7.377 & 7.262 & 0.115 \\
\hline Tlatepexco & 7.22 & 6.79 & 0.43 & 7.373 & 7.223 & 0.151 \\
\hline \multicolumn{7}{|l|}{ San Lorenzo } \\
\hline Tlacoyucan & 7.21 & 7.71 & -0.5 & 7.37 & 7.546 & -0.176 \\
\hline \multicolumn{7}{|l|}{ Ahuatitla (Prol. } \\
\hline Benito Juárez) & 7.18 & 10.14 & -2.96 & 7.359 & 8.736 & -1.376 \\
\hline Tetzumpa & 7.17 & 5.44 & 1.73 & 7.356 & 6.685 & 0.671 \\
\hline \multirow[t]{2}{*}{ Mecalco } & 7.09 & 7.15 & -0.06 & 7.328 & 7.349 & -0.021 \\
\hline & & & & & & continçua > \\
\hline
\end{tabular}


Polis, Revista Latinoamericana, Volumen 11, No 33, 2012

\begin{tabular}{|c|c|c|c|c|c|c|}
\hline Cuacuahotlipa & 7.09 & 7.46 & -0.37 & 7.328 & 7.457 & -0.129 \\
\hline Colonia Teziuhtepec & 7.08 & 8 & -0.92 & 7.324 & 7.653 & -0.328 \\
\hline Huepaltepec & 7.05 & 6.24 & 0.81 & 7.314 & 7.021 & 0.293 \\
\hline Tepetenco & 7.03 & 7.85 & -0.82 & 7.307 & 7.597 & -0.29 \\
\hline Temoclaluca & 7 & 7.83 & -0.83 & 7.297 & 7.59 & -0.293 \\
\hline Carretera a Santa Ana & 7 & 6.8 & 0.2 & 7.297 & 7.226 & 0.07 \\
\hline Prolongación Xolotl & 7 & 7.68 & -0.68 & 7.297 & 7.535 & -0.239 \\
\hline Omaxal & 6.91 & 7.44 & -0.53 & 7.265 & 7.45 & -0.185 \\
\hline La Mora III & 6.84 & 6.89 & -0.05 & 7.24 & 7.258 & -0.018 \\
\hline Santa Rosa & 6.79 & 7.19 & -0.4 & 7.223 & 7.363 & -0.14 \\
\hline San Isidro Cuatepec & 6.76 & 7.35 & -0.59 & 7.212 & 7.419 & -0.207 \\
\hline San Marcos & 6.71 & 6.74 & -0.03 & 7.194 & 7.205 & -0.011 \\
\hline Texacatipac & 6.67 & 7.92 & -1.25 & 7.18 & 7.623 & -0.443 \\
\hline Teacalco & 6.67 & 7.3 & -0.63 & 7.18 & 7.401 & -0.221 \\
\hline Prolongación & & & & & & \\
\hline Justo Sierra & 6.67 & 4 & 2.67 & 7.18 & 5.831 & 1.349 \\
\hline Camino Viejo & & & & & & \\
\hline a Santa Cruz & 6.67 & 7.45 & -0.78 & 7.18 & 7.454 & -0.274 \\
\hline Paraje la Cruz & & & & & & \\
\hline (Camino a Tlaltenami) & 6.67 & 7.04 & -0.37 & 7.18 & 7.311 & -0.131 \\
\hline Texalco & 6.64 & 6.61 & 0.03 & 7.169 & 7.158 & 0.011 \\
\hline Xoctonco & 6.6 & 7.23 & -0.63 & 7.155 & 7.377 & -0.222 \\
\hline Atuzanco & 6.57 & 7.44 & -0.87 & 7.144 & 7.45 & -0.306 \\
\hline Maxulco & & & & & & \\
\hline (Barrio Cruztitla) & 6.54 & 8.03 & -1.49 & 7.133 & 7.664 & -0.531 \\
\hline Quepilco & 6.5 & 7.52 & -1.02 & 7.118 & 7.478 & -0.36 \\
\hline Tlaxala & 6.45 & 7.68 & -1.23 & 7.1 & 7.535 & -0.435 \\
\hline Localidades de & & & & & & \\
\hline dos viviendas & 6.44 & 7.83 & -1.39 & 7.096 & 7.59 & -0.493 \\
\hline Cuyucalco & 6.43 & 7.39 & -0.96 & 7.093 & 7.433 & -0.34 \\
\hline Tetexaloca & 6.43 & 6.19 & 0.24 & 7.093 & 7.002 & 0.091 \\
\hline Barranca Seca (Pozo 8 & & & & & & \\
\hline Camino a San Fco.) & 6.41 & 7.34 & -0.93 & 7.085 & 7.415 & -0.33 \\
\hline Coyocalli & 6.37 & 8.15 & -1.78 & 7.07 & 7.71 & -0.639 \\
\hline Conzontlicpa & 6.35 & 7 & -0.65 & 7.063 & 7.297 & -0.234 \\
\hline Zacamoli & 6.35 & 9.58 & -3.23 & 7.063 & 8.38 & -1.317 \\
\hline Playa Quieta & 6.31 & 8.58 & -2.27 & 7.048 & 7.884 & -0.836 \\
\hline Teatlaco & 6.27 & 4.6 & 1.67 & 7.033 & 6.237 & 0.796 \\
\hline Nuch Huaca & & & & & & \\
\hline (Techinantitle) & 6.25 & 7.07 & -0.82 & 7.025 & 7.321 & -0.296 \\
\hline San Paocotitla & 6.2 & 6.08 & 0.12 & 7.006 & 6.959 & 0.047 \\
\hline Zacuaztitla & 6.15 & 6.45 & -0.3 & 6.986 & 7.1 & -0.114 \\
\hline Paraje Cuauhtetec & 6.02 & 7.23 & -1.21 & 6.935 & 7.377 & -0.442 \\
\hline
\end{tabular}


Primaria

\begin{tabular}{|l|l|l|l|l|l|l|}
\hline & \multicolumn{2}{|l|}{$\begin{array}{l}\text { ESCOLARIDAD } \\
\text { PROMEDIO }\end{array}$} & DIFERENCIA & \multicolumn{2}{l|}{$\begin{array}{l}\text { ESCOLARIDAD } \\
\text { PROMEDIO }\end{array}$} & DIFERENCIA \\
\hline $\begin{array}{l}\text { Itzintlantepetl } \\
\text { (Calle Bugambilias) }\end{array}$ & 5.95 & 7.07 & -1.12 & 6.907 & 7.321 & -0.414 \\
$\begin{array}{l}\text { Tlaloxtoc } \\
\text { (Ejidos de Tecoxpa) }\end{array}$ & 5.9 & 6.38 & -0.48 & 6.886 & 7.074 & -0.188 \\
Prolongación las Cruces & 5.9 & 7.14 & -1.24 & 6.886 & 7.345 & -0.459 \\
Atoctienco & & & & & & \\
(Camino a la Mina) & 5.85 & 7.11 & -1.26 & 6.866 & 7.335 & -0.469 \\
Prolongación Belisario & & & & & & \\
Domínguez (El Pirul) & 5.8 & 6.29 & -0.49 & 6.845 & 7.04 & -0.196 \\
Totolan & 5.79 & 6.81 & -1.02 & 6.84 & 7.23 & -0.389 \\
Prolongación Zaragoza & & & & & & \\
(Olla de Piedra) & 5.78 & 7.38 & -1.6 & 6.836 & 7.429 & -0.593 \\
Tetzmititla & 5.67 & 8.64 & -2.97 & 6.789 & 7.91 & -1.121 \\
Prol. San Marcos & & & & & & \\
(Tamasquiti) & 5.63 & 6.15 & -0.52 & 6.771 & 6.986 & -0.215 \\
Cuapalipa & 5.59 & 4.24 & 1.35 & 6.753 & 6.003 & 0.75 \\
Tecpallo & 5.59 & 7.28 & -1.69 & 6.753 & 7.394 & -0.641 \\
La Mora V & 5.58 & 3.5 & 2.08 & 6.749 & 5.426 & 1.323 \\
Zacaticli & 5.57 & 5.85 & -0.28 & 6.744 & 6.866 & -0.121 \\
Acatlaco & 5.44 & 5.43 & 0.01 & 6.685 & 6.68 & 0.005 \\
La Mora & 5.42 & 8.5 & -3.08 & 6.675 & 7.85 & -1.175 \\
Tlaxiomulco & 5.38 & 4.96 & 0.42 & 6.657 & 6.444 & 0.213 \\
Paraje Oluca & 5.31 & 6.22 & -0.91 & 6.623 & 7.014 & -0.391 \\
Pitucaltitla & 5.3 & 4.2 & 1.1 & 6.618 & 5.976 & 0.642 \\
Coametzu & 5.25 & 4.93 & 0.32 & 6.594 & 6.427 & 0.166 \\
Tlalcocomoya & 5.22 & 7.68 & -2.46 & 6.579 & 7.535 & -0.957 \\
Mecatzintla & 5.19 & 6.84 & -1.65 & 6.564 & 7.24 & -0.677 \\
Prolongación Avenida & & & & & & \\
México Norte & 5.13 & 5.9 & -0.77 & 6.533 & 6.886 & -0.353 \\
Tetecolok & 5.11 & 7.42 & -2.31 & 6.523 & 7.443 & -0.92 \\
Hueycotzingo & 4.75 & 7 & -2.25 & 6.326 & 7.297 & -0.971 \\
Rancho los Capulines & 4.63 & 5.73 & -1.1 & 6.255 & 6.815 & -0.56 \\
Texcalahuitiel & 4.21 & 7.81 & -3.6 & 5.983 & 7.582 & -1.6 \\
Tototepec & 2.27 & 5.79 & -3.52 & 4.098 & 6.84 & -2.742 \\
Tlachachalipac & 1.89 & 5.08 & -3.19 & 3.576 & 6.507 & -2.931 \\
\hline & & & & & & \\
\hline
\end{tabular}




\section{Notas}

${ }^{1}$ Para una revisión del modelo básico de Solow, así como la revisión de esta sección de la investigación véanse (Jones, 2000) y (Sala-i-Martin, 2000).

${ }^{2}$ Nótese que h está dividida entre L o trabajo no calificado

${ }^{3}$ Para una revisión más afondo de esto véanse (Barro y Sala-i-Martin, 1992), (Sala-i-Martin, 2000) y (Vilalta, 2003).

${ }^{4}$ Esto se realizó únicamente para los 112 asentamientos irregulares de Milpa Alta que eran comparables entre el 2000-2005. Solo basta recordar que el proceso por el cual fueron establecidos estos como asentamientos irregulares se debe más a una decisión política que al mercado de suelo o tenencia de la propiedad, puesto que en este caso se considero establecer una demarcación arbitraria que dejo algunos asentamientos dentro de lo que se considero los cascos urbanos y a los otros fuera de ellos a los cuales se les considero como asentamientos irregulares.

${ }^{5}$ Existe una teoría llamada de Credencialización que se opone a la idea de que la formación educativa per se traiga consigo grandes beneficios a quien invierte en educación, puesto según las credenciales educativas, esto es: dónde se estudio y con quién se estudió y el historial educativo (promedio, materias, actividades extracurriculares, etc.), trae consigo los beneficios de la inversión en educación al fijarse los contratantes en estas características, para el caso véase (Blaug, 1985).

${ }^{6}$ Para el caso de la relación entre libertad-educación y desarrollo véase (Sen, 2000).

${ }^{7}$ Un importante grupo de personas que habitan en la delegación Milpa Alta se hacen llamar “originarios", porque son descendientes directos de los primeros pobladores de la zona. Esta categoría lejos de ser constrictiva se aplica con la finalidad de excluir a aquellos que no cuentan "supuestamente" con los mismos derechos que los originarios.

${ }^{8}$ Esto realizado a través del método de componentes principales, lo cual hace diferir los resultados obtenidos de distancias porcentuales en relación con el índice de desarrollo humano estimado por la ONU. En este caso se rechaza el uso del ingreso per cápita pero se refuerza el rubro de escolaridad con la tasa promedio de escolaridad y la asistencia escolar cuando esto se requiere.

${ }^{9}$ Lo cual es consistente con el análisis de Convergencia presentado más adelante.

${ }^{10}$ Es necesario tomar en consideración que los parámetros obtenidos para el desarrollo humano sólo dependen de las unidades de análisis, es decir es un nivel relativo a los asentamientos irregulares y no guarda relación con otras delegaciones, ni siquiera con los asentamientos en cascos urbanos de la delegación, en cuyo caso los parámetros obtenidos serían menores dado que las condiciones de vida en los cascos urbanos de Milpa Alta u otras delegaciones del Distrito Federal la población se encuentra en mejor situación. 


\section{Bibliografía}

Barceinas, Fernando y José Luis Raymond (2002), Convergencia regional y capital humano en México de los años 80 al 2002, Mimeo, México.

Barro, Robert y Xavier Sala-i-Martin (1992), “Convergence”, en: The Journal of Political Economy, University of Chicago, volumen 100, núm. 2, Chicago, USA.

Becker, Gary (1983), El capital humano: Un análisis teórico y empírico referido fundamentalmente a la educación, Alianza, Madrid.

Ídem y Nashat, Guity (2002), La economía cotidiana, Planeta, México.

Blaug, Mark (1985). “La teoría del capital humano” en: Blaug, Mark, La metodología de la economía o cómo explican los economistas, Alianza, Madrid.

Calderón Cuahutémoc y Anna Tykhonenko (2006), “La liberación económica y la convergencia regional en México” en: Comercio exterior, Bancomex, volumen 56 número 5, México.

INEGI (2000 y 2005), Banco de Información Electrónica de Localidades, INEGI, México.

Jones, Charles (2000), Introducción al crecimiento económico, Prentice Hall, México.

Krugman, Paul (1996), La organización espontánea de la economía, Antoni Bosch, Barcelona.

Leyva, Soraya y Antonio Cárdenas (2002), “Economía de la educación: capital humano y rendimiento educativo”, en: Análisis Económico, Universidad Autónoma Metropolitana-Azcapotzalco, volumen XVII, núm. 36, México.

Marx, Karl (1977), El Capital: crítica de la economía política, Librerías Allende, TomosI y II, México.

Sala-i-Martin, Xavier (2000), Apuntes de crecimiento económico, Antoni Bosch, Barcelona.

Schultz, Theodore (1985), Invirtiendo en la gente, Ariel, Barcelona.

Sen, Amartya (2000), Desarrollo y libertad, Planeta, México.

Vilalta, Carlos (2003), “Una aplicación del análisis espacial al estudio de 
Polis, Revista Latinoamericana, Volumen 11, $N^{\circ}$ 33, 2012

las diferencias regionales del ingreso en México”, en: Economía, sociedad y territorio, Volumen IV núm. 14, México.

Recibido: 28.05.2011

Aceptado: 30.04.2012 